\title{
Two colliding epidemics - obesity is independently associated with chronic pain interfering with activities of daily living in adults 18 years and over; a cross-sectional, population-based study
}

\author{
Sharon A. Allen ${ }^{1 *}$, Eleonora Dal Grande ${ }^{2}$, Amy P. Abernethy ${ }^{3,4}$ and David C. Currow ${ }^{1,3}$
}

\begin{abstract}
Background: Chronic pain interfering with activities of daily living is highly prevalent in the community. More than 600 million people worldwide are obese. The aim of this paper is to assess if such chronic pain is associated independently with obesity across the adult population, having controlled for other key factors.

Methods: The South Australian Health Omnibus is an annual, population-based, cross-sectional study. Data on 2616 participants were analysed for episodes of daily pain for three of the preceding six months. Obesity was derived from self-reported height and weight. Multivariable logistic regression analysed the associations between chronic pain interfering with activities of daily living, body mass index (BMI) and key socio-demographic factors.

Results: Chronic pain interfering with activities of daily living peaks in people $\geq 75$ years of age while obesity peaks in the 45-54 age group. Pain and obesity together peak in the 55-74 year age group. In the adjusted multinominal logistic regression model, compared to those with no pain, there was a strong association between obesity and pain that interfered moderately or extremely with day-to-day activities (OR 2.25; $95 \% \mathrm{Cl} 1.57-3.23 ; p<0.001$ ) having controlled for respondents' age, gender, rurality, country of birth and highest educational attainment. People over 65 years of age and those with lower educational levels were more likely to experience such chronic pain related to obesity.

Conclusion: This study demonstrates a strong association between chronic pain and obesity/morbid obesity in the South Australian population. Prospective, longitudinal data are needed to understand the dynamic interaction between these two prevalent conditions.
\end{abstract}

Keywords: Pain, Obesity, Period prevalence, Impaired activities of daily living, Population survey

\section{Background}

Chronic pain is a prevalent problem in today's society with recent evidence showing the incidence across the community is continuing to rise even in adolescents, with prevalence of between 14-24 \% [1]. Incidence increases through the ageing process, with a range reported between 28 and $61 \%$ in elderly adults

\footnotetext{
* Correspondence: Sharon.Allen2@sa.gov.au

${ }^{1}$ Southern Adelaide Palliative Services, Repatriation General Hospital, Daw

Park, Adelaide, South Australia

Full list of author information is available at the end of the article
}

depending on definitions and the population surveyed $[2,3]$. Chronic pain in this current study is defined as 'an episode of pain most days for more than three of the last six months' [2].

The World Health Organisation (WHO) report that more than 1.9 billion adults globally were considered overweight with 600 million people identified as obese in 2014. This has more than doubled as a proportion of the world's population since 1980 [4]. Adding to the concern of the global burden of obesity is that in 2013, 42 million children under the age of 5 were overweight 
or obese, indicating that the high rate of obesity is set to continue and health-related consequences will be seen in health systems globally. The WHO has also reported that obesity is no longer a problem only in high income countries, with low and middle income countries now facing an obesity epidemic and the health burdens with which obesity is associated [4].

Studies have demonstrated an association between obesity and a variety of chronic pain concerns including musculoskeletal dysfunction, headaches and neuropathic pain $[5,6]$. The association of pain and obesity was recently confirmed in a systematic review [7]. Further, where mechanical impacts of obesity may be causing pain, weight loss has been shown to reduce pain subsequently [7]. A recent five year longitudinal study in an elderly cohort of 1099 participants confirmed a relationship between fat mass, body mass index (BMI) and likelihood of experiencing pain [8]. Although fat mass and BMI were both associated with multiple sites of chronic pain, only BMI was associated with lower back pain [8]. This is consistent with an 11 year longitudinal study in the elderly that demonstrated the strong relationship between obesity, chronic disease, ageing and what the authors termed 'chronic widespread pain' [9]. Whilst the pathophysiology is unclear, and likely complicated by the multifactorial nature of chronic pain [10], studies have highlighted that patients with both obesity and chronic pain are more likely to experience disability and impact on their activities of daily living, though the mechanisms by which this relationship is mediated are complex and variable $[3,11,12]$. To date, most studies seeking to define the association between chronic pain and obesity do so from the view point of people who have contact with health services (for joint replacement, with chronic pain services or obesity services for example). Many studies are also limited by the age of the cohort studied and, although many studies establish the presence of pain, few outline its impact on day-to-day function by measuring interference with the activities of daily living.

The aim of this study is to examine whether obesity is an independent association of chronic pain that interferes with activities of daily living in all adult ages independently of their health service contact, controlling for socioeconomic status, and other demographic factors. The null hypothesis is that there is no association between chronic pain that interferes with activities of daily living and obesity across the population having controlled for key socio-demographic factors.

\section{Methods}

\section{Setting}

South Australia is a state with $7 \%$ of the Australian population and is, on average, slightly older than the rest of the country, and has a slightly lower proportion of people who were born in other countries.

\section{Sample}

Data were collected using the 2006 South Australian Health Omnibus Surveys (HOS) [13, 14]. HOS is a multi-stage, systematic, clustered area sample of households conducted face-to-face annually in spring based on the Australian Bureau of Statistics (ABS) collector districts (CDs). The 2006 HOS sample included households randomly selected from CDs, from the metropolitan Adelaide area and country towns with a population of 1,000 people or more. Within each $\mathrm{CD}$, a random starting point was selected and from this point 10 households were then selected in a given direction with a fixed skip interval. Hotels, motels, hospitals, hostels and other institutions were excluded from the sample. An approach letter introducing the survey was sent to the selected households. One person, aged 15 years and over, who was last to have a birthday, was selected from each household for interview. The interviews were conducted in people's homes by trained interviewers and up to six call-back visits were made to the chosen households in an attempt to interview the selected person. There was no replacement by another person within the household when the selected member of the household did not want to participate. In total, 2969 people participated, achieving a response rate of $55 \%$. The data were weighted by five year age group, sex, rurality (metropolitan Adelaide compared to SA country) and household size to the Australian Bureau of Statistics' 2005 Estimated Residential Population for South Australia to provide population estimates.

\section{Self-reported pain}

Each respondent was asked, over the last six months, if he/she had "an episode of pain that has lasted more than three months". An episode of pain was defined as "pain experienced on most days" over that period. The following options on a prompt card were given:

1. No

2. Yes, I did get pain but it did not interfere with my day-to-day activities

3. Yes, I did get pain and it interfered a little bit with my day-to-day activities

4. Yes, I did get pain and it interfered moderately with my day-to-day activities

5. Yes, I did get pain and it interfered extremely with my day-to-day activities.

\section{Data for respondents' body mass index (BMI)}

Body mass index (BMI) was derived from self-reported weight and height with answers accepted in metric or imperial measures. BMI was calculated using the formula, kilograms/metres ${ }^{2}$, and recoded into three categories (underweight/normal weight, overweight and 
obese) as defined by WHO [15]. The classification was used for people aged 15 to 17 years and recoded into three categories (normal weight, overweight and obese) [16].

\section{Socio-demographic measures}

Demographic variables included age, sex, rurality (metropolitan/rural), country of birth, highest level of education, marital status, gross annual household income and current work status.

\section{Statistical analyses}

Data analysis was conducted using Statistical Package for Social Sciences (SPSS) for Windows Version 19.0 and Stata Version 13. All estimates and analyses used population weighted data. The analysis was restricted to those who answered questions related to an episode of pain and who provided their height and weight $(n=2616)$. From the five levels of pain categories, respondents were classified into three groups: no pain, pain but no interference (none to a little bit of interference with day-to-day activities) and regular pain that interferes (moderately to extreme interference with day-to-day activities). Univariable analyses compared the proportion of respondents in each of the three pain groups across socio-demographic indicators.

Multinomial logistic regression models were created to analyse ordered episodes of pain (no pain, pain but no interference, or regular pain that interferes) as the dependent variable with three classifications of BMI (nor$\mathrm{mal} /$ underweight; overweight; and obese), adjusting for age group, sex and rurality, highest educational attainment and country of birth. Marital status was notincluded since this variable was highly correlated with other sociodemographic variables (collinearity). Co-morbidities such as osteoporosis, diabetes and arthritis were not included in the regression model as they were considered to be on the causal pathway, and by including these in the model, the association between BMI and episode of pain will largely be attenuated. Possible interaction terms were considered for inclusion in the regression model but were none were considered to be clinically practical.

Ethical approval for the project was obtained from the South Australian Department of Health's ethics committee. All participants gave verbal informed consent and continued participation in the face-to-face interview was accepted as continued consent.

\section{Results}

One quarter of the respondents $(24.6 \% ; n=664)$ experienced an episode of pain that lasted more than three of the last six months (Table 1). Of those people, $54.3 \%$ had pain that did not interfere or only interfered a little bit with their daily activities and $45.7 \%$ had pain that interfered moderately $(25.6 \%$ or $6.5 \%$ of the total population) or extremely ( $n=18.7 \%$ or $4.7 \%$ of the total population) with their daily activities. Chronic pain interfering with activities of daily living peaked in the population over 75 years of age (Fig. 1).

Three pain groups were compared by socio-demographic indicators and health conditions (Table 2). Generally, respondents experiencing pain but no interference with their daily lives were more likely to be female, in the older age groups, widowed, and diagnosed with co-morbid illnesses. Respondents experiencing regular pain that interfered with their daily lives were more likely to be: obese; older; separated, divorced or widowed; having lower educational qualifications; living in a household with lower incomes; and diagnosed with current comorbid conditions.

Obesity and morbid obesity was seen in $21.6 \%(n=564)$ of the population. By age group, obesity peaked in the 45-54 year old age group where one third of all respondents were obese or morbidly obese.

In the adjusted multinominal logistic regression model (Table 3), compared to those with no pain, there was a strong association between obesity and pain that interfered moderately or extremely with day-to-day activities (OR 2.25; 95 \% CI 1.57, 3.23; $p<0.001$ )

\section{Discussion}

This study demonstrated that people who were obese were more than twice as likely to have pain that interfered moderately or extremely with activities of daily living having controlled for key socio-demographic factors. Importantly, the rate of pain interfering with activities of daily living is consistent with a previous study of pain interfering extremely with activities of daily living with a quoted rate from the same state of Australia of $5.0 \%$ [17]. A recently published cross-sectional population study of 2508 people from Germany demonstrated very similar rates of chronic pain interfering with activities of daily living ( $7.3 \%$; $95 \%$ CI $5.9 \%, 8.7 \%)$ and the odds ratio (2.14; 95 \% CI $5.9 \%, 7.8 \%$ ) for an association with obesity [18].

When reviewing the association between BMI and chronic pain, we distinguished between being overweight and being obese and, likewise, between pain that did and did not interfere with people's activities of daily living. For less troublesome pain, there was no association with being overweight nor obese (Table 3). These findings are consistent with other studies key studies [19-21].

Most population studies in this field highlight trends that chronic pain is more likely to be reported in females, elderly participants and those in lower socioeconomic settings, reflecting these findings from South Australia. In a recent nine country, cross-sectional study, all 9 countries demonstrated higher education and wealth as a protective factor in chronic pain in the 
Table 1 Prevalence and sample sizes for episode of pain, BMl and covariates

Analysis sample $(n=2616)$

Episode of pain that has lasted

more than 3 months

\begin{tabular}{|c|c|c|}
\hline No & 1972 & $75.4(73.7-77.0)$ \\
\hline $\begin{array}{l}\text { Yes, not interfere with day-to-day } \\
\text { activities }\end{array}$ & 162 & $6.2(5.3-7.2)$ \\
\hline $\begin{array}{l}\text { Yes, interfere a little bit with day-to-day } \\
\text { activities }\end{array}$ & 188 & $7.2(6.3-8.3)$ \\
\hline $\begin{array}{l}\text { Yes, interfere moderately with day-to-day } \\
\text { activities }\end{array}$ & 170 & $6.5(5.6-7.5)$ \\
\hline $\begin{array}{l}\text { Yes, interfere extremely with day-to-day } \\
\text { activities }\end{array}$ & 124 & $4.7(4.0-5.6)$ \\
\hline \multicolumn{3}{|l|}{ Body mass index } \\
\hline Normal/underweight & 1204 & $46.0(44.1-48.0)$ \\
\hline Overweight & 848 & $32.4(30.7-34.2)$ \\
\hline Obese & 564 & $21.6(20.0-23.2)$ \\
\hline \multicolumn{3}{|l|}{ Demographics characteristics } \\
\hline \multicolumn{3}{|l|}{ Sex } \\
\hline Male & 1326 & $50.7(48.8-52.6)$ \\
\hline Female & 1290 & $49.3(47.4-51.2)$ \\
\hline \multicolumn{3}{|l|}{ Age } \\
\hline $15-24$ & 385 & $14.7(13.4-16.1)$ \\
\hline $25-34$ & 409 & $15.6(14.3-17.1)$ \\
\hline $35-44$ & 483 & $18.5(17.0-20.0)$ \\
\hline $45-54$ & 477 & $18.2(16.8-19.8)$ \\
\hline $55-64$ & 372 & $14.2(12.9-15.6)$ \\
\hline $65-74$ & 286 & $10.9(9.8-12.2)$ \\
\hline $75+$ & 203 & $7.7(6.8-8.8)$ \\
\hline \multicolumn{3}{|l|}{ Area of residence } \\
\hline Metropolitan & 1952 & $74.9(73.2-76.5)$ \\
\hline Regional & 656 & $25.1(23.5-26.9)$ \\
\hline \multicolumn{3}{|l|}{ Marital status } \\
\hline Married/De Facto & 1701 & $65.0(63.2-66.8)$ \\
\hline Separated/Divorced & 211 & $8.1(7.1-9.2)$ \\
\hline Widowed & 134 & $5.1(4.3-6.0)$ \\
\hline Never Married & 561 & $21.4(19.9-23.0)$ \\
\hline Not stated & 10 & $0.4(0.2-0.7)$ \\
\hline \multicolumn{3}{|l|}{ Country of birth } \\
\hline Australia & 1906 & $72.8(71.1-74.5)$ \\
\hline UK/reland & 327 & $12.5(11.3-13.8)$ \\
\hline Other & 384 & $14.7(13.4-16.1)$ \\
\hline \multicolumn{3}{|l|}{ Educational attainment } \\
\hline Up to secondary & 1145 & $43.8(41.9-45.7)$ \\
\hline Trade, Apprenticeship, Certificate, Diploma & 995 & $38.0(36.2-39.9)$ \\
\hline Degree or higher & 467 & $17.9(16.4-19.4)$ \\
\hline Not stated & 9 & $0.4(0.2-0.7)$ \\
\hline
\end{tabular}

Table 1 Prevalence and sample sizes for episode of pain, BMl and covariates (Continued)

\begin{tabular}{lll}
\hline Employment status & & \\
Work full or part time & 1516 & $57.9(56.0-59.8)$ \\
Home Duties & 231 & $8.8(7.8-10.0)$ \\
Unemployed & 55 & $2.1(1.6-2.7)$ \\
Retired & 516 & $19.7(18.2-21.3)$ \\
Student & 175 & $6.7(5.8-7.7)$ \\
Not working because work related injury & 124 & $4.7(4.0-5.6)$ \\
or disability, other & & \\
Annual household income & & \\
Up to \$20,000 & 330 & $12.6(11.4-13.9)$ \\
\$20,001 to \$50,000 & 625 & $23.9(22.3-25.6)$ \\
\$50,001 to \$80,000 & 539 & $20.6(19.1-22.2)$ \\
\$80,001 or more & 644 & $24.6(23.0-26.3)$ \\
Not stated & 478 & $18.3(16.8-19.8)$ \\
\hline
\end{tabular}

2616 participants from the 2006 South Australian Omnibus Survey met the inclusion criteria for this study. $24.6 \%$ of respondents $(n=664)$ reported an episode of pain with a duration of more than three months within the 6 months prior to time of survey. Of the respondents who reported pain, $54.3 \%(n=350)$ stated their pain either did not interfere or only slightly interfered with their activities of daily living. $45.7 \%$ of respondents reporting pain $(n=294)$ stated their pain either moderately or extremely interfered with their activities of daily living

setting of obesity [22]. Interestingly, the female and elderly respondents in our study were more likely to report pain without significant impact on activities of daily living which differs from the findings of the Olmsted study that demonstrated trends in both females and elderly respondents being more likely to report pain impacting on their daily activities of living [3].

Direct correlation and comparison to previous studies is difficult due to the lack of standardisation of the definitional issues with chronic pain which varies from 4 to 12 weeks and researchers' approaches to defining pain severity groupings with a minority reporting the impact on activities of daily living. Furthermore there is considerable difference in population age groups which may affect the overall percentage of individuals reporting significant pain.

Population-based studies can only establish association, not causality. In the dyad of pain that interferes with activities of daily living and obesity, either could initiate the cycle of one worsening the other progressively. In studies of people with both, it is apparent that the model of pain limiting mobility thereby worsening weight control in turn leading to worsening pain or obesity generating pain, limiting mobility and thereby worsening obesity is potentially far too simplistic. A study of people with pain suggests that stress-induced eating is a consequence, in part, of catastrophizing about the longer term outcomes of chronic pain [23]. This may mean that any model seeking to define causes-and-effects is likely to be a complex relationship 


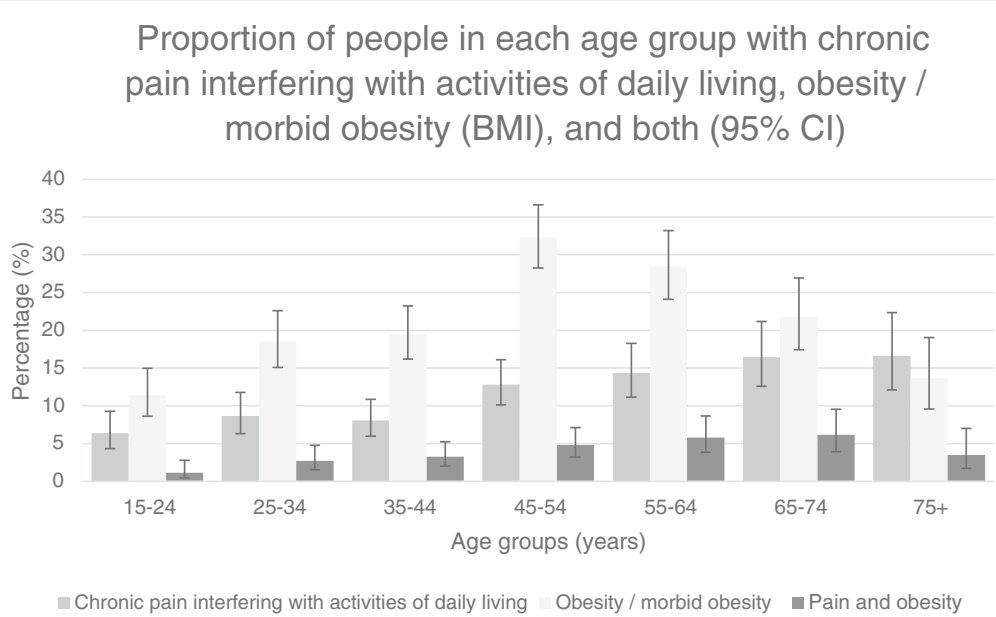

Fig. 1 In 2616 randomly selected community members, proportions with chronic pain interfering with activities of daily living, obesity and both

that requires careful consideration of all the contributing factors. In the setting of women with frequent migraines and obesity, catastrophizing, more frequent and more intense migraines were much more likely than in women who did not have obesity [24].

\section{Limitations of the study}

Our data were collected through self-reported surveys which have several limitations. Firstly, this form of data collection is potentially subject to recall bias, however the bias is consistently measured across the population and the duration of recall sought (6 months) is relatively short. Secondly the calculation of BMI for the study was through self-reported weight and height. Studies indicate that individuals may under-report their weight and overestimate their height leading to likely systematic underestimation of overweight and obesity in this study [13]. Further to this, we have not identified characteristics of adiposity $[21,25,26]$.

Our survey could not explore any links between chronic pain and other associated socio-demographic factors including depression, type of employment, smoking/alcohol status, cultural/ethnic background, private health insurance status or history of abuse/violence $[2,11,12,22,26-28]$.

During this study, we did not approach individuals in hospitals or residential care facilities however we recognise that there is likely to be a large burden of chronic pain in these particular populations.

\section{Further research}

Our study provides supporting evidence to the growing body of research on the prevalence of chronic pain in the Australian population associated with obesity. Recent articles suggesting multifactorial pathogenesis of chronic pain in the obese population (specifically inflammatory mechanisms) would be better supported with further research isolating specific locations of pain (non-weight bearing joints compared with weight bearing joints, upper compared to lower extremity pain) which we have not reviewed as part of our current study $[10,19,20]$.

Furthermore, more detailed assessment of attributes of obesity i.e. waist circumference and calculation of fat mass/free fat mass may help to further the understanding of the aetiology of this combination of symptoms - does one usually precede the other or not? [21, 25] More research into the confounding and contributing comorbidities would be worth further exploration, specifically underlying mental health issues including depression which has been highlighted in multiple studies to have a contributing effect on chronic pain [28].

Finally, longitudinal studies would be beneficial to further our understanding of the genesis and resolution of chronic pain in our society and the impact on activities of daily living over time. For how many people is the obesity a consequence of chronic pain and vice versa?

Clinically, given evidence that weight loss can improve the management of osteoarthritis and its pain (with an aim of delaying or avoiding joint replacement therapy), understanding the genesis of the combination of pain and obesity, and recognising its presence early is a crucial role for all medical practitioners [29].

\section{Conclusion}

There is a strong association between chronic pain and obesity in the South Australian population with individuals identified as obese reporting pain interfering with daily activities twice as frequently as the rest of the population. Direct comparison of the findings of the South Australian population to similar studies is difficult due to lack of standardisation of populations and 
Table 2 Univariable analyses of severity of pain by BMI and covariates (socio-demographic and health-related variables)

\begin{tabular}{|c|c|c|c|c|c|c|c|}
\hline & \multirow{2}{*}{$\begin{array}{l}\text { Total } \\
n\end{array}$} & \multicolumn{2}{|c|}{ No pain } & \multicolumn{2}{|c|}{$\begin{array}{l}\text { Pain but no interference with } \\
\text { day-to-day activities }\end{array}$} & \multicolumn{2}{|c|}{$\begin{array}{l}\text { Regular pain that interferes with } \\
\text { day-to-day activities }\end{array}$} \\
\hline & & $n$ & $\%(95 \% \mathrm{Cl})$ & $\mathrm{n}$ & $\%(95 \% \mathrm{Cl})$ & $\mathrm{n}$ & $\%(95 \% \mathrm{Cl})$ \\
\hline Overall & 2616 & 1972 & $75.4(73.7-77.0)$ & 350 & $13.4(12.1-14.7)$ & 294 & $11.2(10.1-12.5)$ \\
\hline \multicolumn{8}{|l|}{ BMl } \\
\hline Normal/underweight & 1209 & 961 & 79.5 (77.1-81.6) & 151 & $12.5(10.8-14.5)$ & 97 & $8.0(6.6-9.7)$ \\
\hline Overweight & 843 & 632 & 74.9 (71.9-77.7) & 114 & $13.6(11.4-16.0)$ & 97 & $11.5(9.5-13.8)$ \\
\hline Obese & 564 & 379 & $67.3(63.3-71.0)$ & 84 & $14.9(12.2-18.1)$ & 100 & $17.8(14.9-21.2)$ \\
\hline \multicolumn{8}{|l|}{ Covariates } \\
\hline \multicolumn{8}{|l|}{ Sex } \\
\hline Male & 1326 & 1026 & $77.4(75.0-79.5)$ & 155 & $11.7(10.1-13.5)$ & 145 & $10.9(9.4-12.7)$ \\
\hline Female & 290 & 946 & $73.3(70.8-75.7)$ & 195 & $15.1(13.3-17.2)$ & 149 & 11.6 (9.9-13.4) \\
\hline \multicolumn{8}{|l|}{ Age group } \\
\hline $15-24$ & 385 & 331 & $85.9(82.1-89.1)$ & 30 & $7.7(5.4-10.8)$ & 25 & $6.4(4.3-9.3)$ \\
\hline $25-34$ & 409 & 315 & $76.9(72.6-80.7)$ & 59 & $14.5(11.4-18.2)$ & 35 & $8.7(6.3-11.8)$ \\
\hline $35-44$ & 483 & 391 & $80.8(77.0-84.1)$ & 54 & $11.1(8.6-14.3)$ & 39 & $8.1(6.0-10.8)$ \\
\hline $45-54$ & 477 & 352 & $73.8(69.6-77.5)$ & 64 & $13.4(10.6-16.8)$ & 61 & $12.8(10.1-16.1)$ \\
\hline $55-64$ & 372 & 259 & $69.6(64.7-74.0)$ & 60 & $16.1(12.7-20.2)$ & 53 & $14.3(11.2-18.3)$ \\
\hline $65-74$ & 286 & 188 & $65.6(59.9-70.9)$ & 51 & $17.9(13.9-22.8)$ & 47 & $16.4(12.6-21.2)$ \\
\hline $75+$ & 203 & 137 & $67.5(60.8-73.6)$ & 32 & $15.8(11.5-21.5)$ & 34 & $16.6(12.1-22.3)$ \\
\hline \multicolumn{8}{|l|}{ Area of residence (rurality) } \\
\hline Metro. Adelaide & 1952 & 1471 & $75.4(73.4-77.2)$ & 273 & $14.0(12.5-15.6)$ & 208 & $10.7(9.4-12.1)$ \\
\hline SA Country & 656 & 496 & $75.6(72.1-78.7)$ & 75 & $11.5(9.2-14.1)$ & 85 & $13.0(10.6-15.8)$ \\
\hline \multicolumn{8}{|l|}{ Marital status } \\
\hline Married/De facto & 1701 & 1278 & $75.2(73.1-77.2)$ & 234 & $13.7(12.2-15.4)$ & 189 & $11.1(9.7-12.7)$ \\
\hline Separated/Divorced & 211 & 147 & $69.8(63.3-75.6)$ & 28 & $13.4(9.4-18.6)$ & 35 & $16.8(12.4-22.5)$ \\
\hline Widowed & 34 & 90 & $67.1(58.7-74.4)$ & 22 & $16.5(11.1-23.7)$ & 22 & $16.5(11.1-23.7)$ \\
\hline Never married & 561 & 447 & $79.7(76.2-82.8)$ & 66 & $11.8(9.4-14.8)$ & 48 & $8.5(6.5-11.1)$ \\
\hline \multicolumn{8}{|l|}{ Country of birth } \\
\hline Australia & 1906 & 1456 & $76.4(74.4-78.2)$ & 252 & $13.2(11.8-14.8)$ & 198 & $10.4(9.1-11.9)$ \\
\hline UK and Ireland & 327 & 228 & $69.7(64.5-74.4)$ & 49 & $15.1(11.6-19.4)$ & 50 & $15.2(11.7-19.5)$ \\
\hline Other & 384 & 289 & $75.3(70.7-79.3)$ & 49 & $12.7(9.8-16.4)$ & 46 & $12.0(9.1-15.7)$ \\
\hline \multicolumn{8}{|l|}{ Educational attainment } \\
\hline Up to secondary & 145 & 862 & $75.3(72.7-77.7)$ & 148 & $12.9(11.1-15.0)$ & 135 & $11.8(10.1-13.8)$ \\
\hline Trade, Apprenticeship, Certificate, Diploma & 995 & 725 & $72.8(70.0-75.5)$ & 145 & $14.6(12.6-16.9)$ & 125 & $12.5(10.6-14.8)$ \\
\hline Degree or higher & 467 & 384 & $82.1(78.4-85.3)$ & 56 & $12.0(9.4-15.3)$ & 28 & $5.9(4.1-8.4)$ \\
\hline \multicolumn{8}{|l|}{ Household annual income } \\
\hline Up to $\$ 20,000$ & 330 & 216 & $65.4(60.1-70.3)$ & 52 & $15.9(12.4-20.2)$ & 62 & $18.7(14.9-23.3)$ \\
\hline$\$ 20,001$ to $\$ 50,000$ & 625 & 451 & $72.1(68.4-75.4)$ & 87 & $14.0(11.5-16.9)$ & 87 & $14.0(11.5-16.9)$ \\
\hline$\$ 50,001$ to $\$ 80,000$ & 539 & 430 & 79.7 (76.1-82.9) & 66 & $12.2(9.7-15.3)$ & 43 & $8.0(6.0-10.6)$ \\
\hline$\$ 80,001$ or more & 644 & 495 & $76.8(73.4-79.9)$ & 96 & $15.0(12.4-17.9)$ & 53 & $8.2(6.4-10.6)$ \\
\hline Not stated & 478 & 381 & $79.8(75.9-83.1)$ & 48 & $10.0(7.6-13.0)$ & 49 & $10.2(7.8-13.3)$ \\
\hline Overall & 2616 & 1972 & $75.4(73.7-77.0)$ & 350 & $13.4(12.1-14.7)$ & 294 & $11.2(10.1-12.5)$ \\
\hline
\end{tabular}

Respondents were placed into one of three groups indicating if they experienced pain and if the pain impacted on activities of daily living. Respondents reporting pain without an impact on their activities of daily living were more likely to be female in an older age group, widowed and experiencing co-morbid illness. Respondents who reported regular pain interfering with their activities of daily living were more likely to be from an older age group, obese, living in a lower income household and with a lower educational qualification. This group of respondents were also more likely to be living with active comorbid illnesses 
Table 3 Multinomial logistic regression of severity of pain by BMI

\begin{tabular}{|c|c|c|c|c|}
\hline & \multicolumn{2}{|l|}{ Unadjusted } & \multicolumn{2}{|l|}{ Adjusted ${ }^{*}$} \\
\hline & OR $(95 \% \mathrm{Cl})$ & $P$ value & OR $(95 \% \mathrm{Cl})$ & $P$ value \\
\hline \multicolumn{5}{|l|}{ No pain (reference) } \\
\hline \multicolumn{5}{|c|}{ Have pain, no interference to a little bit with day-to-day activities } \\
\hline \multicolumn{5}{|l|}{ BMl } \\
\hline Normal/underweight & 1.00 & & 1.00 & \\
\hline Overweight & $1.13(0.85-1.52)$ & 0.395 & $1.04(0.77-1.40)$ & 0.803 \\
\hline Obese & $1.40(1.02-1.94)$ & 0.040 & $1.30(0.94-1.81)$ & 0.115 \\
\hline \multicolumn{5}{|l|}{ Sex } \\
\hline Male & 1.00 & & 1.00 & \\
\hline Female & $1.34(1.05-1.71)$ & 0.020 & $1.38(1.06-1.79)$ & 0.016 \\
\hline \multicolumn{5}{|l|}{ Age group } \\
\hline 18 to 24 & 1.00 & & 1.00 & \\
\hline 25 to 34 & $1.68(1.03-2.75)$ & 0.039 & $1.68(0.96-2.95)$ & 0.070 \\
\hline 45 to 64 & $2.20(1.36-3.54)$ & 0.001 & $2.10(1.23-3.61)$ & 0.007 \\
\hline $65+$ & $2.79(1.72-4.54)$ & $<0.001$ & $2.71(1.58-4.64)$ & $<0.001$ \\
\hline \multicolumn{5}{|l|}{ Area of residence (rurality) } \\
\hline SA Country & 1.00 & & 1.00 & \\
\hline Metropolitan Adelaide & $1.17(0.87-1.59)$ & 0.296 & $1.33(0.94-1.87)$ & 0.105 \\
\hline \multicolumn{5}{|l|}{ Educational attainment } \\
\hline Degree or higher & 1.00 & & 1.00 & \\
\hline Up to secondary & $1.18(0.84-1.68)$ & 0.341 & $1.12(0.76-1.65)$ & 0.565 \\
\hline Trade, Apprenticeship, Certificate, Diploma & $1.38(0.96-1.97)$ & 0.079 & $1.35(0.92-1.96)$ & 0.120 \\
\hline \multicolumn{5}{|l|}{ Country of birth } \\
\hline Australia & 1.00 & & 1.00 & \\
\hline UK/reland & $1.33(0.94-1.86)$ & 0.105 & $1.03(0.72-1.47)$ & 0.890 \\
\hline Other & $1.11(0.78-1.58)$ & 0.574 & $0.85(0.59-1.24)$ & 0.402 \\
\hline \multicolumn{5}{|c|}{ Have pain, interfere moderately to extremely with day-to-day activities } \\
\hline \multicolumn{5}{|l|}{ BMl } \\
\hline Normal/underweight & 1.00 & & 1.00 & \\
\hline Overweight & $1.50(1.07-2.11)$ & 0.018 & $1.34(0.93-1.92)$ & 0.114 \\
\hline Obese & $2.61(1.84-3.71)$ & $<0.001$ & $2.25(1.57-3.23)$ & $<0.001$ \\
\hline \multicolumn{5}{|l|}{ Sex } \\
\hline Male & 1.00 & & 1.00 & \\
\hline Female & $1.12(0.86-1.46)$ & 0.392 & $1.11(0.83-1.48)$ & 0.475 \\
\hline \multicolumn{5}{|l|}{ Age group } \\
\hline 18 to 24 & 1.00 & & 1.00 & \\
\hline 25 to 34 & $1.62(0.95-2.76)$ & 0.075 & $1.30(0.72-2.35)$ & 0.382 \\
\hline 45 to 64 & $2.70(1.62-4.51)$ & $<0.001$ & $1.94(1.10-3.41)$ & 0.022 \\
\hline $65+$ & $3.59(2.10-6.14)$ & $<0.001$ & $2.69(1.45-4.97)$ & 0.002 \\
\hline \multicolumn{5}{|l|}{ Area of residence (rurality) } \\
\hline SA Country & 1.00 & & 1.00 & \\
\hline Metropolitan Adelaide & $0.81(0.59-1.11)$ & 0.194 & $0.95(0.66-1.36)$ & 0.771 \\
\hline \multicolumn{5}{|l|}{ Educational attainment } \\
\hline Degree or higher & 1.00 & & 1.00 & \\
\hline
\end{tabular}


Table 3 Multinomial logistic regression of severity of pain by BMI (Continued)

\begin{tabular}{llll}
\hline Up to secondary & $1.90(1.23-2.95)$ & 0.004 & $1.87(1.15-3.01)$ \\
Trade, Apprenticeship, Certificate, Diploma & $2.39(1.52-3.75)$ & $<0.001$ & $2.17(1.35-3.51)$ \\
Country of birth & & & 0.011 \\
Australia & 1.00 & 0.001 \\
UK/reland & $1.53(1.06-2.21)$ & 0.022 & $1.30(0.89-1.92)$ \\
Other & $1.27(0.90-1.80)$ & 0.181 & $1.16(0.80-1.68)$
\end{tabular}

The adjusted multinominal logistic regression model demonstrates a strong association between obesity and pain interfering either moderately or extremely with activities of daily living (OR 2.25; $95 \% \mathrm{Cl} 1.57-3.23 ; p<0.001)$. When reviewing the association between obesity and pain with minimal to no interference of activities of daily living no association was identified

$B M I$ Body mass index, OR odds ratio, $\mathrm{Cl}$ confidence interval

*Adjusted by sex, age, area of residence and educational attainment

definitions in other key studies on this topic. The South Australian cohort did have similar trends of socioeconomic advantage and higher educational status being protective factors while, at a population level, being identified as female, elderly and with a lower socio-economic demographic increased the likelihood of reporting chronic pain with obesity. Prospective, longitudinal data are needed to understand the dynamic interactions between these two prevalent risk health states in order to understand better their interplay.

\section{Abbreviations}

ABS: Australian Bureau of Statistics; BMI: Body mass index; CD: Collector Districts; Cl: Confidence Interval; HOS: Health Omnibus Survey; OR: Odds Ratio; SPSS: Statistical Package for Social Sciences; WHO: World Health Organisation

\section{Acknowledgments}

With thanks to Prof Anne Taylor, The University of Adelaide, for the obesity data, and Prof Katherine Clark, The University of Newcastle, and A/Prof Melanie Lovell, The University of Sydney, for the helpful comments on this manuscript.

\section{Funding}

This study was supported by discretionary funds held by the Discipline, Palliative and Supportive Services at Flinders University.

\section{Availability of data and material}

The Health Omnibus Survey (HOS) is a user-pay survey in which various organisations pay for their questions to be included in the surveys. Because of this, the authors of this study do not own all of the HOS data and permission had to be sought from each owner, therefore data are not publicly available. The data directly owned by the research team are available to other bona fide researchers by contacting David.Currow@sa.gov.au

\section{Authors' contributions}

DC, AA conception and design, EDG acquisition of data, SA, EDG, DC, AA analysis and interpretation of data, SA, EDG, DC drafting of manuscript, all authors read and approved the final manuscript.

\section{Competing interests}

The authors have no conflicts of interest to disclose in relation to this manuscript.

\section{Consent for publication}

Not Applicable

\section{Ethical approval and consent to participate}

Ethical approvals were obtained from the Research Ethics Committees of The University of Adelaide and the South Australian Department of Health. Participation in the study is voluntary. Verbal informed consent was obtained from participants at the start of the interview. Prior to contact by the interviewers, a primary approach letter was sent to the household informing the household of the purpose of the survey including confidentiality and privacy assurance, that participation is voluntary, and a contact number for queries. Upon initial contact, interviewers repeat the purpose of the survey as well as the expected length of time to complete the interview.

\section{Author details}

${ }^{1}$ Southern Adelaide Palliative Services, Repatriation General Hospital, Daw Park, Adelaide, South Australia. ${ }^{2}$ Population Research and Outcomes Studies Unit, Discipline of Medicine, Health Sciences Faculty, Adelaide University, Adelaide, Australia. ${ }^{3}$ Discipline, Palliative and Supportive Services, Flinders University, Bedford Park, Adelaide, South Australia. ${ }^{4}$ Division of Medical Oncology, Department of Medicine, Duke University Medical Centre, Durham, North Carolina, USA.

Received: 9 May 2016 Accepted: 22 September 2016

Published online: 30 September 2016

\section{References}

1. Deere K, Clinch J, Holliday K, McBeth J, Crawley EM, Sayers A, Palmer S, Doerner R, Clark EM, Tobias JH. Obesity is a risk factor for musculoskeletal pain in adolescents: Findings from a population-based cohort. Pain. 2012; 153(9):1932-8

2. McCarthy L, Bigal M, Katz M, Derby C, Lipton R. Chronic pain and obesity in elderly people: Results from the Einstein aging study. J Am Geriatrics Soc. 2009;57(1):115-9.

3. Watkins EA, Wollan PC, Melton 3rd LJ, Yawn BP. A population in pain: report from the Olmsted county health study. Pain Med. 2008:9(2):166-74.

4. World Health Organisation. Obesity and overweight. Fact sheet 311. 2015; http://www.who.int/mediacentre/factsheets/fs311/en/. Accessed 24 March 2016.

5. Ray L, Lipton R, Zimmerman M, Katz M, Derby C. Mechanisms of association between obesity and chronic pain in the elderly. Pain. 2011;152(1):53-9.

6. Wilson A, Samuelson B, Palermo T. Obesity in children and adolescents with chronic pain: Associations with pain and activity limitations. Clin J Pain. 2010;26(8):705-11.

7. Narouze S, Souzdalnitski D. Obesity and chronic pain: systematic review of prevalence and implications for pain practice. Reg Anesth Pain Med. 2015; 40(2):91-111.

8. Pan F, Laslett L, Blizzard L, Cicuttini F, Winzenberg T, Ding C, Jones G. Associations between fat mass and multi-site pain: A 5-year longitudinal study. Arthritis Care Res (Hoboken). 2016 Jul 7. Epub ahead of print

9. Mundal I, Gråwe RW, Bjørngaard JH, Linaker OM, Fors EA. Prevalence and long-term predictors of persistent chronic widespread pain in the general population in an 11-year prospective study: the HUNT study. BMC Musculoskelet Disord. 2014:15:213.

10. Paley C, Johnson M. Physical Activity to Reduce Systemic Inflammation Associated with Chronic Pain and Obesity: A narrative review. Clin J Pain. 2016;32(4):365-70

11. Arranz $L$, Rafecas $M$, Alegre $C$. Effects of obesity on function and quality of life in chronic pain conditions. Curr Rheumatol Rep. 2014;16(1):390.

12. Stone AA, Broderick JE. Obesity and pain are associated in the United States. Obesity (Silver Spring). 2012;20(7):1491-95. 
13. Taylor AW, Dal Grande E, Wilson DH. The South Australian Omnibus Survey 15 years on: has public health benefited? Public Health Bulletin. 2006;3:30-2.

14. Wilson D, Wakefield M, Taylor AW. The South Australian Omnibus survey. Health Promotion J of Aust. 1992:2:47-9.

15. World Health Organisation. Obesity: Preventing and managing the global epidemic. Report of a WHO Consultation (WHO Technical Report Series 894) 2000; http://www.who.int/nutrition/publications/obesity/WHO_TRS_894/en/. Accessed 24 March 2016.

16. Cole TJ, Bellizzi MC, Flegal KM, Dietz WH. Establishing a standard definition for child overweight and obesity worldwide: international survey. BMJ. 2000; 320(7244):1240.

17. Currow DC, Agar M, Plummer JL, Blyth FM, Abernethy AP. Chronic pain in South Australia -population levels that interfere extremely with activities of daily living. Aust NZ J Pub Hlth. 2010;34(3):232-9.

18. Häuser W, Schmutzer G, Hilbert A, Brähler E, Henningsen P. Prevalence of chronic disabling noncancer pain and associated demographic and medical variables: A cross-sectional survey in the general german population. Clin J Pain. 2015;31(10):886-92.

19. Brady S, Mamuaya B, Cicuttini F, Wluka AE, Wang Y, Hussain SM, Urquhart DM. Body composition is associated with multisite lower body musculoskeletal pain in a community-based study. J Pain. 2015;16(8):700-6.

20. Ott U, Stanford J, Thiese M, Murtaugh MA, Greenwood JL, Gren LH, Garg A, Hegmann KT. Two Industrial Cohorts: baseline characteristics and factors associated with obesity. J Occup Environ Med. 2015:57(5):562-70.

21. Yoo JJ, Cho NH, Lim SH, Kim HA. Relationships between body mass index, fat mass, muscle mass, and musculoskeletal pain in community residents. Arthritis Rheumatol. 2014;66(12):3511-20.

22. Koyanagi A, Stickley A, Garin N, Miret M, Ayuso-Mateos JL, Leonardi M, Koskinen S, Galas A, Haro JM. The association between obesity and back pain in nine countries: a cross-sectional study. BMC Public Health. 2015;15:123.

23. Janke EA, Jones E, Hopkins CM, Ruggieri M, Hruska A. Catastrophizing and anxiety sensitivity mediate the relationship between persistent pain and emotional eating. Appetite. 2016;103:64-71.

24. Bond DS, Buse DC, Lipton RB, Thomas JG, Rathier L, Roth J, Pavlovic JM, Evans EW, Wing RR. Clinical Pain Catastrophizing in women with migraine and obesity. Headache. 2015;55(7):923-33.

25. Kissebah AH, Vydelinfum N, Murray R, Evans DJ, Hartz AJ, Kalkhoff RK, Adams PW. Relation of body fat distribution to metabolic complications of obesity. J Clin Endocrinol Metab. 1982;54(2):254-60.

26. Somers T, Wren A, Keefe F. Understanding chronic pain in older adults: Abdominal fat is where it is at. Pain. 2011;152(1):8-9.

27. Kamaleri Y, Natvig B, Ihlebaek C, Benth J, Bruusgaard D. Number of pain sites is associated with demographic, lifestyle, and health-related factors in the general population. Eur J Pain. 2008;12(6):742-8.

28. van Hecke O, Torrance N, Smith BH. Chronic pain epidemiology and its clinical relevance. Br J Anaesth. 2013;111(1):13-8.

29. Bijlsma JW, Knahr K. Strategies for the prevention and management of osteoarthritis of the hip and knee. Best Pract Res Clin Rheumatol. 2007; 21(1):59-76

\section{Submit your next manuscript to BioMed Central and we will help you at every step:}

- We accept pre-submission inquiries

- Our selector tool helps you to find the most relevant journal

- We provide round the clock customer support

- Convenient online submission

- Thorough peer review

- Inclusion in PubMed and all major indexing services

- Maximum visibility for your research

Submit your manuscript at www.biomedcentral.com/submit

BioMed Central 